\title{
Keystone Microbiome in the Rhizosphere Soil Reveals the Effect of Long-Term Conservation Tillage on Crop Growth in the Chinese Loess Plateau
}

\section{Lijuan Jia}

Chinese Academy of Agricultural Sciences

\section{Zhen Wang}

Chinese Academy of Agricultural Sciences

Lei Ji

Chinese Academy of Agricultural Sciences

\section{Stefaan De Neve}

Ghent University

C. Struik Paul

Wageningen University and Research

\section{Yuqing Yao}

Luoyang Academy of Agriculture and Forestry Sciences

\section{Junjie Lv}

Luoyang Academy of Agriculture and Forestry Sciences

\section{Tao Zhou}

Ningxia Academy of Agriculture and Forestry Sciences

Ke Jin ( $\nabla$ jinke@caas.cn )

Chinese Academy of Agricultural Sciences Grassland Research Institute

\section{Research Article}

Keywords: long-term conservation tillage, co-occurrence network, redundancy analysis, keystone microbiome, winter wheat

Posted Date: August 19th, 2021

DOl: https://doi.org/10.21203/rs.3.rs-786735/v1

License: (c) (1) This work is licensed under a Creative Commons Attribution 4.0 International License. Read Full License 
Version of Record: A version of this preprint was published at Plant and Soil on March 11th, 2022. See the published version at https://doi.org/10.1007/s11104-022-05297-5. 
1 Keystone microbiome in the rhizosphere soil reveals the effect of long-term conservation tillage

3 Lijuan $\mathrm{Jia}^{\# 1,2}$, Zhen Wang ${ }^{\# 1}$, Lei $\mathrm{Ji}^{1}$, Stefaan De $\mathrm{Neve}^{3}$, Paul C. Struik ${ }^{4}$, Yuqing Yao ${ }^{5}$, Junjie $\mathrm{Lv}^{5}$, Tao

4 Zhou $^{6}, \mathrm{Ke} \operatorname{Jin}^{1,2^{*}}$

$5 \quad{ }^{1}$ Grassland Research Institute, Chinese Academy of Agricultural Sciences, Hohhot, China, 010010

$6 \quad{ }^{2}$ Key Laboratory of Nonpoint Source Pollution Control, Ministry of Agriculture, P.R. China, 100080

7

Research, Wageningen, Netherlands

10

${ }^{5}$ Luoyang Academy of Agriculture and Forestry Sciences, Henan Province, China, 471023

11

${ }^{6}$ Ningxia Academy of Agriculture and Forestry Sciences, Ningxia Hui Autonomous Region, China,

12

750002

13

14

*Corresponding author:

15

E-mail: jinke@caas.cn

${ }^{\#}$ These authors contributed equally to this work. 
Abstract

Purpose Keystone taxa play an important role in soil nutrient cycling and crop growth and can be influenced by soil tillage. We investigated the composition of keystone taxa and their relationships with soil properties under different long-term tillage practices.

Methods Four tillage treatments were applied (i.e., CT, conventional tillage; NT, no tillage with mulch; RT, reduced tillage; and SS, subsoiling with mulch), maintained for 21 years. Co-occurrence network (CoNet) was constructed to identify the keystone taxa, and redundancy analysis (RDA) was carried out to explore the relationships between keystone taxa and soil properties under four tillage practices at two growth stages (elongation and grain filling stages) of winter wheat.

Results Compared with CT, RT had no significant effect on the microbial community and the keystone microbiome, while NT and SS remarkably altered the microbial community structure and the keystone microbiome at both crop stages. Massilia was the keystone genus under CT and RT, while Sphingomonas, Asanoa and Hoeflea were the keystone genera under NT and SS. RDA results showed that keystone genera were significantly correlated with soil organic carbon (SOC), dissolved organic carbon (DOC) and microbial biomass nitrogen (MBN) at both stages, but especially at the elongation stage. Our results further revealed that the effects of NT and SS on crop growth might be related to the changes in keystone microbiome.

Conclusion Our study suggests that NT and SS were suitable conservation regimes and may contribute to the development of sustainable agricultural production in the Chinese Loess Plateau.

Keywords: long-term conservation tillage; co-occurrence network; redundancy analysis; keystone 
microbiome; winter wheat 


\section{Introduction}

Winter wheat (Triticum aestivum L.) is one of the largest and most important food crops in China (Sun et al. 2018a), and its yield contributes more than $70 \%$ of the agricultural production in the arid area (Xia et al. 2020). The Loess Plateau, spanning 64 million hectares in northwestern China, is a major arid farming area (Chen et al. 2015). High nutrient losses (e.g., soil C, N and P) and low nutrient utilization efficiency constrain the improvement of winter wheat production, making development of a sustainable agriculture in this region difficult (Niu et al. 2020). Therefore, improvement of storage of nutrients in the soil and enhancing use efficiency are essential to increase winter wheat production (Ali et al. 2019; Jin et al. 2008; Yan et al. 2020).

Soil tillage is a vital cultural practice to control soil water, soil nutrients, and soil temperature (Yang et al. 2018). In many dry regions, conversion from conventional tillage to conservation tillage is a promising strategy to improve soil structure (Martínez et al. 2013; Pareja-Sánchez et al. 2017), preserve soil water (Jin et al. 2007, 2008), and enhance the accumulation of SOC (Sun et al. 2018a; Thomas et al. 2019; Wang and Zou 2020a). For instance, it has been shown that long-term no tillage with mulch (NT) improved the capacity of the soil to store and conserve water, to increase the content of dissolved organic carbon and available nutrients through retaining more crop residues (Singh et al. 2019); subsoiling with mulch (SS) also proved to be an effective strategy to increase soil water content by stimulating water infiltration, and increasing soil carbon and nitrogen concentrations (Wang et al. 2020b); reduced tillage (RT) also served as a conservation tillage practice and could increase the content of SOC by reducing the number of tillage operations. These increases are the most important 
factors contributing to winter wheat production enhancement ( $\mathrm{Lu}$ and Liao 2017; Sun et al. 2018a;

Yang et al. 2018). However, the underlying mechanisms of these benefits for winter wheat growth under long-term conservation tillage are not well understood.

Rhizo-bacterial activities largely manipulate crop development, nutrient absorption, and soil health (Mickan et al. 2019). The crop growth promotion of rhizo-bacteria has been proven in tomato (Ngoma et al. 2013), rice (Rangjaroen et al. 2015), maize (Naveed et al. 2014), and wheat (Duran et al. 2014). In addition, rhizo-bacteria create an interface between soil and crop roots (Semenov et al. 2020). In most cases, rhizo-bacteria are involved in the decomposition processes of nutrients (i.e., $\mathrm{C}, \mathrm{N}$ and $\mathrm{P}$ ) in the soil, and thus increase the supply of resources for crop growth (Wang et al. 2017a). Therefore, management of rhizo-bacteria offers an opportunity to enhance the sustainability of the agroecosystem. However, optimization of a specific and useful rhizo-bacterium during the development of a crop is a daunting task given the complexity of the interactions among microorganisms (Deng et al. 2012). Agler et al. (2016) developed the concept of "keystone taxa" to describe the taxa that were closely associated with many other taxa within the soil microbiome. Their findings prove that such highly connected microbes are important for plant health, as they mediate the feedback of plant and microbiome. In terms of this view, keystone taxa might recruit beneficial microorganisms or prevent invasion of pathogen in order to improve their fitness, for the benefit of the whole system. Therefore, information about rhizo-bacterial interactions can be organized, the analysis of microbiome can be simplified, and the key role of individual species in microbiome can be identified by focusing on keystone taxa (Herren and McMahon 2018). To date, keystone taxa have been identified in many environments such 
as forests (Hartmann et al. 2014), deserts (Zhou et al. 2020), and grasslands (Banerjee et al. 2018), by defining the degree of node-specific interactions between taxa within co-occurrence networks (Fisher and Mehta 2014). However, studies on keystone taxa in arid farming systems are still lacking.

To the best of our knowledge, research efforts on arid agroecosystems focused more on the effect of tillage practices on the rhizo-bacterial community composition (Tyler 2019; Xia et al. 2020; Wang et al. 2016). These studies consistently indicated that the relative abundances of Proteobacteria and Actinobacteria were increased by conservation tillage (e.g., NT, SS and RT), while Acidobacteria were reduced. Moreover, the shift of in the rhizo-bacterial community related to the number of years a tillage system was maintained. For example, studies that focused on the effects of 5 (Wang et al. 2016), 6 (Wang et al. 2017a), and 10 (Wang et al. 2020c) years of no tillage on the rhizo-bacterial community structure indicated that the effects of no tillage on rhizo-bacterial composition changed between 5 and 10 years (e.g., from Proteobacteria-dominated to Actinobacteria-dominated). Other research demonstrated that a 14-year RT caused low soil water retention, and consequently selected for specific species (Tyler 2019). However, the lasting effect of long-term tillage (e.g., 21 years) on rhizo-bacteria remains unclear.

In addition to the tillage regimes, the growing season of a crop is another driver of change in the rhizo-bacterial community structure in agricultural systems (Spedding et al. 2004; Zhang et al. 2018). Root system development during the growing season and associated changes in rhizodeposition, i.e., exudation of crop roots of inorganic $\mathrm{C}$ into the soil, may alter the spatial distribution and quality of organic compounds, influencing the dynamics of the rhizo-bacterial community over time (Baetz and 

growth of winter wheat.

Martinoia 2014; Jones et al. 2009). Many researchers have investigated the roles of tillage practices and crop growth in mediating the rhizo-bacterial community (Shi et al. 2013; Spedding et al. 2004). However, the results of these researches are often inconsistent. Shi et al. (2013) reported that the tillage effects on the rhizo-bacteria were dependent on the growing season, but Spedding et al. (2004) found there were no interactive effects between tillage and growing season. Therefore, further investigations are needed to deepen our knowledge about the relationship between tillage and crop growth in regulating the rhizo-bacterial community.

Our previous study showed that NT and SS had pronounced positive effects on yield and soil physicochemical properties after 8 consecutive years in the Loess Plateau of China, where winter wheat (cv. Yumai 48) was cultivated (Jin et al. 2008). However, the underlying microbial mechanisms of these promising effects remained unknown. In this study, we separately constructed eight co-occurrence networks (CT-, NT-, RT-, and SS-CoNet at each of two growth stages, i.e., the elongation stage (Zadoks stage 31) and the grain filling stage (Zadoks stage 85) of winter wheat) based on high-throughput sequencing to identify the keystone genera under different tillage practices that had been maintained for 21 years. The objective of this study were 1) to compare the relative abundance and composition of keystone genera and complexity of microbial network in different tillage treatments; 2) to examine the correlations between soil available nutrients and keystone genera under long-term conservation tillage practices; 3) to reveal the microbial mechanisms of the effect of long-term conservation tillage on the 
Site description

An experimental station was set up in Songzhuang Village, $25 \mathrm{~km}$ north of the city of Luoyang,

Henan Province (113.08 East longitude, 34.58 North latitude), in the eastern part of the Loess Plateau,

China, in 1999. In this region, Quaternary loess has accumulated to a thickness of approximately

silty loam, classified as an Inceptisol according to Soil Taxonomy. In order to assess plot homogeneity, conducted by Jin et al. (2009).

The experimental tillage treatments were assigned to individual plots. Each experimental unit was $3 \mathrm{~m}$ wide by $90 \mathrm{~m}$ long with a $0.5 \mathrm{~m}$ guard row on both sides. Four tillage practices were applied: conventional tillage (CT), no tillage with mulch (NT), reduced tillage (RT), and subsoiling with mulch (SS). All four tillage treatments were cropped with winter wheat (cv. Yumai 48) in a continuous cropping monoculture, and the different tillage practices were applied consistently on the same experimental plots from 1999 onwards. Detailed information about each tillage practice was given in

136 Jin et al. (2009). Equal fertilizer rates based on common fertilizer practices were applied in each plot in 
138

139

140

141

142

basal fertilizer before sowing. In CT, fertilizer was broadcast and then incorporated into the soil immediately before sowing. For NT, RT, and SS, fertilizer was applied at sowing by direct drilling. Protection against insects (mainly budworm) was ensured with the application of the systemic organophosphorus insecticide omethoate $\left(\mathrm{C}_{5} \mathrm{H}_{12} \mathrm{NO}_{4} \mathrm{PS}\right)$ at a dose of $1125 \mathrm{~mL}$ active compound ha-1.

\section{Sampling strategy}

Twenty winter wheat plants were selected from each plot at the elongation stage (Zadoks stage 31) and grain filling stage (Zadoks stage 85). To reduce the differences in the effect of root depth and the damage to the field plot, we collected the roots at $0-20 \mathrm{~cm}$ depth. Then, all roots of each plot were shaken vigorously to remove any soil not tightly adhering to them (Song et al. 2007; Wang et al. 2017b). Three replicate composite rhizosphere soil samples (three subsamples were separately taken from each experimental unit and homogenized to form a composite sample) were taken for each treatment. Rhizosphere soil samples were sieved through a 2-mm mesh, and were divided into three sub-samples, placed on dry ice, and rapidly shipped to the laboratory. One sub-sample was oven-dried and used to determine the soil moisture, a second sub-sample was air-dried to assess soil physicochemical properties, and a third sub-sample was immediately frozen at $-80{ }^{\circ} \mathrm{C}$ for DNA extraction and 16S rRNA gene MiSeq-sequencing. The winter wheat samples corresponding to the rhizosphere soil samples were air-dried to measure biomass and yield. 
The biomass and yield of selected winter wheat were assessed after air-drying by weighing.

159

160

161

162

Rhizosphere soil pH was measured using a pH meter (HI 2221 Calibration CheckPh/ORP Meter, Hanna Instruments, Woonsocket, RI, USA). Briefly, $5 \mathrm{~mL}$ distilled water was added to $1 \mathrm{~g}$ air-dried soil and placed in a shaker for $18 \mathrm{~h}$ before $\mathrm{pH}$ measurement. The soil water content (WT) was measured by drying $10 \mathrm{~g}$ soil at $105^{\circ} \mathrm{C}$ for $12 \mathrm{~h}$.

Microbial biomass carbon (MBC) was measured using the fumigation extraction technique (Zuber and Villamil 2016). Briefly, soil samples were fumigated with ethanol-free $\mathrm{CHCl}_{3}$. Control samples (non-fumigated) were also assessed. Fumigated and non-fumigated samples were extracted with $0.5 \mathrm{M}$ $\mathrm{K}_{2} \mathrm{SO}_{4}$. The extracts were bubbled with $\mathrm{CO}_{2}$-free air to remove the $\mathrm{CHCl}_{3}$ (Gregorich et al. 1990). MBC was calculated as the difference between fumigated and non-fumigated soil (Álvaro-Fuentes et al. 2013). Dissolved organic carbon (DOC) was measured in the non-fumigated soil using a $\mathrm{TOC} / \mathrm{TNb}$ analyzer (Analytik Jena AG, Jena, Germany). Soil organic carbon (SOC) was determined by dichromate oxidation of $0.5 \mathrm{~g}$ of air-dried soil in $20 \mathrm{~mL}$ concentrated $\mathrm{H}_{2} \mathrm{SO}_{4}$ and $5 \mathrm{~mL} \mathrm{~K}_{2} \mathrm{Cr}_{2} \mathrm{O}_{7}(\mathrm{Cania}$ et al. 2019). Total nitrogen (TN) was measured with an Element Auto-Analyzer (Vario MAX CN; Elementar, Langenselbold, Germany) (Zhang et al. 2016). Nitrate nitrogen $\left(\mathrm{NO}_{3}{ }^{-}-\mathrm{N}\right)$ and ammonium nitrogen $\left(\mathrm{NH}_{4}{ }^{+}-\mathrm{N}\right)$ were extracted following the method described by López-Bellido et al. (2014). Briefly, $50 \mathrm{~mL}$ of $2 \mathrm{~mol} \mathrm{~L}^{-1} \mathrm{KCl}$ was added to $10 \mathrm{~g}$ of dry soil, and the concentrations of $\mathrm{NO}_{3}^{-}-\mathrm{N}$ and $\mathrm{NH}_{4}{ }^{+}-\mathrm{N}$ were determined using a continuous flow colorimeter analyzer (QUAATRO; BranLuebbe, Norderstedt, Germany). Finally, the sum concentration of $\mathrm{NO}_{3}{ }^{-}-\mathrm{N}$ and $\mathrm{NH}_{4}{ }^{+}-\mathrm{N}$ was defined as available nitrogen (AN). The microbial biomass nitrogen (MBN) was measured in $10 \mathrm{~g}$ of fumigated and 
178

179

180

181

182

non-fumigated soil: the soil was extracted with $0.5 \mathrm{M} \mathrm{K}_{2} \mathrm{SO}_{4}$, and the $\mathrm{MBN}$ content was calculated using a $k_{\mathrm{N}}$ factor of 0.45 (Zhang et al. 2016). Soil total phosphorus (TP) and available phosphorus (AP) were determined using $0.5 \mathrm{M} \mathrm{H}_{2} \mathrm{SO}_{4}-\mathrm{HClO}$ and $0.5 \mathrm{M} \mathrm{NaHCO}$, respectively, following the molybdenum blue method.

\section{DNA extraction, PCR, and 16S rRNA gene MiSeq-sequencing}

Environmental DNA was extracted using the E.Z.N.A. Soil DNA Kit (Omega Bio-tek, Inc., Norcross, GA, USA) according to the manufacturer's protocols. The concentration and quality of DNA were determined using a NanoDrop 2000 spectrophotometer (Thermo Fischer Scientific, Waltham, MA, USA). The $16 \mathrm{~S}$ rDNA V3-V4 region was amplified with primers $338 \mathrm{~F}$ and $805 \mathrm{R}$ according to the method of Essel et al. (2019) (Table S1). Amplicons were extracted from 2\% agarose gels and purified using the AxyPrep DNA Gel Extraction Kit (Axygen Biosciences, Union City, CA, USA), following the manufacturer's instructions. Sequencing was performed on an Illumina MiSeq PE300 instrument according to the standard protocols. The sequences were further analyzed using USEARCH v5.2.32 to filter and denoise the data by clustering sequences with $<3 \%$ dissimilarity, and have been submitted to the NCBI Sequence Read Archive (SRA) (https://www.ncbi.nlm.nih.gov/sra/MW237661) with accession number MW237661. Operational taxonomic units (OTUs) were clustered at a $\geq 97 \%$ similarity threshold using the UPARSE pipeline (Schlatter et al. 2019). 

represent correlations between OTUs. Degree represents the connectivity between one node with others were defined as "keystone geanera".

214 SPSS Inc., Somers, USA). Significance level of differences among samples was determined using

215 Tukey's test $(P<0.05)$. 
218

219

220

221

222

was based on the Bray-Curtis method. Redundancy analysis (RDA) was performed to explore the relationship between keystone genera and environmental variables under different tillage practices at two growth stages.

\section{Results}

Soil physicochemical properties and winter wheat biomass and yield

After 21 years of persistent tillage treatments, there were no significant differences in soil $\mathrm{pH}$ among different tillage practices at both growing periods (Table 1). WT, SOC, TN, TP, DOC, AN, MBC and MBN were similar between RT and CT, but significantly higher under NT and SS compared with CT $(P<0.05)$. At the elongation stage, the contents of DOC, MBC and MBN significantly improved by $153.6 \%, 42.1 \%$ and $93.9 \%$ under NT, and improved by $192.2 \%, 54.6 \%$ and $106.7 \%$ under SS, respectively, compared with those under CT. At grain filling, the contents of DOC, MBC and MBN significantly increased by $142.5 \%, 32.6 \%$ and $57.6 \%$ under NT, the significant increases under SS were $149.1 \%, 29.6 \%$ and $63.5 \%$.

There was no significant difference in winter wheat biomass between CT and RT, whereas an obvious increase was observed under NT and SS at both stages $(P<0.05)$ (Fig. S1a). The biomass at the elongation stage was $28.1 \%$ higher for NT and $31.4 \%$ higher for SS treatment than for CT. At grain filling stage, the biomass was $8.5 \%$ was higher for NT and $10.6 \%$ higher for SS than for CT. Yield of winter wheat was also significantly higher for NT and SS $(P<0.05)$, and increased by $5.3 \%$ and $6.1 \%$, respectively, compared with CT (Fig. S1b). 
Microbial community structure and composition

The NMDS plots showed that microbial samples from CT and RT as well as those from NT and

241 SS were closely clustered (stress $=0.042$ ), indicating that the community structures were different

242 under NT and SS compared with CT, but not different from those under RT (Fig. 1). At phylum level,

243 rhizo-bacteria were mainly composed of Proteobacteria, Actinobacteria and Acidobacteria (Fig. 2a).

244 There was no difference in the relative abundance of Proteobacteria under all tillage practices at both stages. The relative abundance of Acidobacteria was significantly higher under NT and SS than under

CT and RT, with values up to 0.22 and 0.20 for NT and SS, respectively, and 0.12 and 0.14 for CT and

RT, respectively, at the elongation stage. The differences in relative abundance of this phylum among

significantly higher in NT and SS than in CT and RT $(P<0.05)$. The relative abundance of Actinobacteria showed a different result, reaching values of 0.20 and 0.21 for NT and SS, respectively, and values of 0.30 and 0.27 for $\mathrm{CT}$ and RT, respectively, at the elongation stage. At the grain filling stage, the relative abundances of this phylum were 0.30 and 0.31 for NT and SS, and were 0.34 and 0.37 for CT and RT, respectively. At genus level, rhizo-bacteria were composed of Massilia, Streptomyces, Pseudarthrobacter and Nocardioides in all treatments at both stages (Fig. 2b). Their relative abundances were significantly decreased by NT and SS $(P<0.05)$. Massilia was the most dominant genus. At the elongation stage, its relative abundance was 0.07 and 0.06 in NT and SS, 
258

259

260

261

filling stage, the relative abundance of Massilia was lower under NT (0.02) and SS (0.02) than that under CT (0.04) and RT (0.04). There were no significant differences in other genera among tillage practices in both stages.

Keystone microbiome in the rhizosphere soil

Co-occurrence network (CoNet) analysis was used to explore the effect of tillage practices on the keystone microbiome and network complexity during both growth stages (Table S2). At the elongation stage, the number of nodes was 238 under CT, but was higher for the other tillage treatments: 240,306 and 264 for RT, NT and SS, respectively. At the grain filling stage, the number of nodes was 308 for CT, but higher for NT and SS, with values of 359 and 381, respectively, while value of 276 for RT, and lower than CT. Links within a network represented interactions among different OTUs, with the fewest links being recorded in CT at the elongation stage (216) and the grain filling stage (345). The number of links was higher for NT (294) and SS (291), at the elongation stage, and increased to 403 (NT) and 408 (SS) at the grain filling stage, indicating that the network structure became more complex for NT and SS compared with CT.

According to the phylogenetic taxonomy of nodes in the network, two main phyla, including Proteobacteria and Actinobacteria, were detected in the four tillage treatments and two growth stages

(Fig. 3). The proportion of Proteobacteria was highest under SS, reaching $60 \%$ and $50 \%$, while it was lowest under NT, reaching $17 \%$ and $33 \%$ at the elongation stage and grain filling stage, respectively. For Actinobacteria, the proportion under tillage practices depended on growth stages. At the elongation 
stage, CT (50\%) showed the highest proportion of Actinobacteria, whereas NT $(28 \%)$ had the lowest.

279

280

281

282

283

284

285

286

287

The proportion of Actinobacteria exhibited an opposite result at the grain filling stage. At genus level, the composition of keystone taxa was similar for CT and RT, as well as for NT and SS, while in NT and SS they were distinctly different from those in CT and RT. Iamia, Rubrobacter, Steroidobacter, Devosia, Massilia and Mesorhizobium commonly existed in CT and RT networks, and Sphingomonas commonly existed in NT and SS networks at the elongation stage. At the grain filling stage, Pseudarthrobacter and Saccharothrix were found in both CT and RT networks, and Asanoa and Hoeflea were found in both NT and SS networks.

\section{Correlations between keystone microbiome and environmental variables}

Significant correlations were observed between some keystone genera and SOC, DOC and MBN under tillage practices during winter wheat growth $(P<0.01)$, which was revealed by redundancy analysis (RDA) (Fig. 4). At the elongation stage, the first axis and the second axis explained 43.84\% and $2.47 \%$ of the variations in keystone microbiome. SOC, DOC and MBN positively correlated with Sphingomonas, Steroidobacter and Solirubrobacter, and negatively correlated with Massilia, Devosia and Streptomyces (Fig. 4a). At grain filling stage, the first axis and the second axis explained 29.24\% and $1.53 \%$ of the variations in keystone microbiome. Significant positive correlations were recorded for Sphingomonas, Steroidobacter and Solirubrobacter with SOC, DOC and MBN, whereas these parameters negatively correlated with Massilia, Devosia and Streptomyces. 
298

\section{Discussion}

Long-term conservation tillage shapes the rhizo-bacterial community structure

Previous studies have demonstrated that the rhizo-bacterial community structure differed in response to different tillage practices (Hartman et al. 2018; Sun et al. 2020; Wang et al. 2017c). In the present study, there were no significant differences in rhizo-bacterial community structure between CT and RT or between NT and SS. However, NT and SS led to considerable changes in community structure when compared with CT and RT (Fig. 1). The results for the relative abundance of dominant phyla and genera in our study explained this difference among tillage practices (Fig. 2). At phylum level, the relative abundances of Actinobacteria and Acidobacteria were similar between CT and RT as well as between NT and SS. While the relative abundances of these two phyla under NT and SS were significantly different from those under CT and RT (Fig. 2a). The difference in Actinobacteria among tillage practices may be attributed to the changes in relative abundance of dominant genera, including Streptomyces, Pseudarthrobacter and Nocardioides, which belonged to the phylum Actinobacteria (Fig. 2b). In Acidobacteria, all corresponding genera were unidentified taxa because the sequencing was not deep enough to cover all taxa, and thus deepening the sequencing is further needed (Sun et al. 2018b). In addition, CoNet results showed that Massilia, Streptomyces, Pseudarthrobacter and Nocardioides were identified as keystone genera in the rhizosphere soil, and significant differences in the degree for these keystone genera were observed under NT and SS relative to CT and RT (Table S3), which led to remarkable changes in the complexity of the networks (Barberán et al. 2012). Consistently, the function of keystone genera displayed a similar pattern with network complexity in response to tillage practices 
(Fig. 3). Massilia and Sphingomonas were capable of promoting plant growth (Bell et al. 2018;

Muangchinda et al. 2015), for example by secreting IAA or siderophores by Massilia (Ofek et al. 2012), and secreting gibberellin, abseisin and salicylic acid by Sphingomonas (Asaf et al. 2020; Bibi et al. 2012). In addition, Sphingomonas members contribute to the solubilization of soil $\mathrm{P}$ to meet $\mathrm{P}$ demand of plants (Rangjaroen et al. 2015). These results indicate that the mechanisms of Massilia and Sphingomonas were different in stimulating the growth of the wheat crop. In the current study, Massilia was a keystone genus in both CT and RT, while Sphingomonas was a keystone genus in both NT and SS (Fig. 3). Therefore, it can be concluded that the transition in the rhizo-bacterial community after changes in tillage could be a result of changes in network complexity and function of keystone genera.

The findings further indicated that the effects of NT and SS on the rhizo-bacterial community gradually decrease with winter wheat growth (Fig. 1). The seasonal changes in community structure could be explained by the variations in the relative abundance of growth-sensitive phyla and genera (Fig. 2), but also by the changes in the keystone genera and network complexity (Table S2). This implied that growth dynamics can mediate the relationship between tillage and rhizo-bacterial community structure. Our results are supported by Shi and his colleagues (2013), who proposed that the effect of tillage on soil bacteria depended on crop growth stage. More important, our results indicated that the effect of NT and SS on the biomass of winter wheat became smaller at the grain filling stage, which further revealed that winter wheat growth related to keystone genera under NT and SS (Fig. S1). Our study highlighted the vital role of crop growth in the effect of tillage on rhizo-bacterial community, and allowed us to better manipulate the rhizo-bacteria during the crop 
338

339

growing season. In the present study, we only analyzed the biomass of winter wheat root during winter wheat growth (Fig. S1). It is recommended that future research should be devoted to unraveling other characteristics of root, including the root length and vigor, and their correlations with rhizo-bacteria, to elucidate how crop growth stage mediate the effect of tillage on the rhizo-bacterial community.

It is well documented that tillage effects on rhizo-bacterial community are highly associated with soil physical and chemical properties (Chang et al. 2021; Kaurin et al. 2018; Wang et al. 2017a, 2020a). The CT treatment can lead to loss of soil nutrients because it largely disrupts the soil structure and removes crop residues (Bu et al. 2020). We also found that the content of soil nutrients, including those of SOC, TN, TP, DOC, AN and AP, did not show significant differences between CT and RT (Table 1). Under RT, one tillage operation was cancelled compared with $\mathrm{CT}$, demonstrating that reducing tillage by one operation could not result in an appreciable effect on soil properties. Our previous study also showed a similar result, as this study was conducted on the same site after 8 years of tillage treatments (Jin et al. 2008). It is also noted that NT had an effect comparable to the effect of SS on these soil parameters (Table 1). In NT, the absence of any tillage practices resulted in accumulation of nutrients, while the soil was not inverted, only loosened to break up compaction under SS; thus a similar soil nutrient content was observed between NT and SS (Bu et al. 2020; Sheehy et al. 2015). However, NT and SS exhibited significantly higher soil nutrient contents (i.e., SOC, TN, TP, DOC and AN) compared with CT and RT (Table 1), which might be attributed to the low soil disturbance and to the retention of crop residues on the soil surface (Yang et al. 2018). Rhizo-bacteria have a preference for nutrient utilization, for instance, a number of copiotrohic groups rapidly grow in soils with high 
358

359

360

361

362

363

nutrient concentrations; in contrast, oligotrophic groups rapidly grow in soils with low nutrient concentrations (Ofek et al. 2012). Thus, we suggest that soil nutrients are one of the factors mediating the changes in rhizo-bacterial community. The seasonal shift in rhizo-bacterial community under NT and SS related to the seasonal changes in soil nutrients, such as DOC.

\section{Long-term conservation tillage drives keystone microbiome by altering SOC, DOC and MBN}

In this study, the compositions of keystone genera were similar for NT and SS and for CT and RT, while they were significantly different for NT and SS in comparison with CT and RT (Fig. 3). This is expected and probably due to the differences in soil variables among tillage practices (Wang et al. 2020c, 2020d). Therefore, we further investigated the interactions between keystone genera and soil properties by redundancy analysis (RDA), showing that SOC, DOC and MBN were significantly correlated with a part of the keystone genera $(P<0.01)$ (Fig. 4). It is noteworthy that our statistically analysis indicated that SOC, DOC and MBN were significantly higher under NT and SS than under CT and RT (Table. 1). These results together indicated that NT and SS select specific keystone genera by altering SOC, DOC and MBN. Several mechanisms could be responsible for this finding. Firstly, NT and SS led to a low disturbance of the soil; in contrast, CT and RT overturned the soil, although the second tillage operation before sowing was cancelled under RT (Hou and Li 2019). Lower soil disturbance under NT and SS reduced runoff by slowing down the water flow over the soil surface, consequently accelerating accumulation of soil organic matter (SOM) (Wang et al. 2020b). Secondly, soil temperature is one of the factors triggering SOM mineralization (Razavi et al. 2016). Under NT 
378

379

380

381

382

383

384

385

386

and SS, the stubble height was higher than under CT and RT, and together with the straw retention, this decreased the radiation at the soil surface, thus reducing soil temperature (Yang et al. 2018). The activity of soil enzymes, which stimulate the mineralization of SOM, decreases with decreasing temperature, thus slowing down the mineralization of SOM (Bowles et al. 2014). Accumulated SOM directly improves the content of SOC, DOC and MBN because SOM is mainly composed of these parameters (Evangelou et al. 2020). Thirdly, decomposed crop residue was the main source of SOC, DOC and MBN when straw was applied to the soil surface (Wang et al. 2020d). Although winter wheat straw was not mixed into the soil under NT and SS, we believe that the decomposed straw at the soil interface was gradually incorporated into the soil (Chen et al. 2014), which was indicated by increased SOC, DOC and MBN in NT and SS treatments (Table 1). In our study, all keystone genera involved the decomposition of SOM (Thiessen et al. 2013), the SOM sensitivity of keystone genera can be varied due to their preferred utilization for nutrients (Qiu et al. 2018; Wang et al. 2016). RDA results showed that SOC, DOC and MBN were positively correlated with Sphingomonas, and were negatively correlated with Massilia (Fig. 4). This might be attributed to the fact that Sphingomonas is a copiotrophic bacterium, and soils with high SOC, DOC and MBN promote the growth of this genus (Bell et al., 2018). In the case of Massilia, soils with low SOC, DOC and MBN promote the growth of this genus because Massilia is an oligotrophic bacterium (Swarnalakshmi et al. 2019). Therefore, Sphingomonas was a keystone genus under NT and SS, while Massilia was a keystone genus under CT and RT (Fig. 3). Our results revealed that reducing the number of tillage operations by one under RT would not lead to significant changes in soil properties, keystone genera, or even crop growth, whereas NT and SS significantly improved soil properties, selected beneficial taxa, and consequently promoted 
399

400

401

crop growth. Although the role of keystone genera in promoting crop growth is well documented in other research, we only estimated the composition of keystone genera in this study, their mechanisms in promoting crop growth under conservation tillage therefore still need to be assessed.

This study also demonstrated that NT and SS effects vary across the growing season and that differences become smaller towards the grain filling stage, which was expressed by the differences in complexity of the network within keystone genera (Table S2), indicating that the effects of NT and SS on keystone genera are regulated by crop growth (Shi et al. 2013). Zhao et al. (2020) reported that root exudates of crop were closely correlated with rhizo-bacteria, and the changes in the composition and quantity of root exudates were depended on crop growth. Grain filling stage of winter wheat presents the reproductive stage, the root vigor in this stage is lower than during the elongation stage, resulting in a lower root exudation rate (Tang et al. 2021). Previous research has illustrated that root exudates were mainly composed of carbon-containing metabolites, such as sugars, amino acids and organic acids, and displayed a slight change at the grain filling stage (Iannucci et al. 2021). These substrates can stimulate the accumulation of DOC and MBN (Cheng et al. 2014). According to these observations, we suggest that DOC and MBN have a weaker response to NT and SS at the grain filling stage. Consistently, our results showed that the smaller effects of NT and SS on DOC and MBN in this stage (Table 1). Moreover, less significant correlations between keystone genera and DOC and MBN were observed at the grain filling than at the elongation stage by the RDA analysis (Fig. 4), which further explains the weak effects of NT and SS on the keystone genera at the grain filling stage. Overall, NT and SS influenced keystone genera through altering the content of SOC, DOC and MBN. Our future work 
419

420

421

should be focused on the root exudates under conservation tillage during winter wheat growth, to reveal how keystone genera respond to crop growth under conservation tillage practices.

\section{Conclusion}

There was no significant difference in microbial community between RT and CT at both growth stages after 21 years at the present site. However, NT and SS significantly influenced the microbial community. In addition, the complexity of the microbial network was remarkably enhanced by NT and SS, meanwhile selecting more keystone genera that were beneficial for crop growth. NT and SS showed indirect effects on the composition of keystone genera by altering SOC, DOC and MBN. We suggest against sampling at a single stage throughout crop growth, as we found differences in the response of keystone genera to NT and SS between elongation stage and grain filling stage. Our study also revealed that NT and SS affect winter wheat growth by shaping unique keystone genera. Overall, NT and SS were suitable conservation regimes and may contribute to the development of sustainable agricultural production in the Chinese Loess Plateau. Our findings enhance the understanding of the role of long-term conservation tillage in altering winter wheat growth and knowledge of specific keystone genera in regulating the growth of winter wheat in the Chinese Loess Plateau.

\section{Acknowledgments}

This work was supported by the open fund of Key Laboratory of Nonpoint Source Pollution Control, Ministry of Agriculture; National Natural Science Foundation of China (grant number 32071861, 42077054); Natural Science Foundation of Inner Mongolia (grant number 2019ZD008); and 
CAAS-Ningxia Regional Cooperation Fund.

\section{Declaration of competing interest} relationships that could have influenced the work reported in this paper.

\section{Author Contributions}

- Lijuan Jia conceived and designed the experiments, performed the experiments, analyzed the data, contributed reagents/materials/analysis tools, prepared figures and/or tables, authored or reviewed drafts of the paper, and approved the final draft.

-Zhen Wang conceived and designed the experiments, performed the experiments, collected soil draft. 
457

458

459

460

461

462

463

464

465

466

467 Ali SA, Tedone L, Verdini L, Cazzato E, De Mastro G (2019) Wheat response to no-tillage and

468 nitrogen fertilization in a long-term faba bean-based rotation. Agron $\mathrm{J}$ 9:1-18.

469 https://doi.org/10.3390/agronomy9020050

470 Álvaro-Fuentes J, Morell FJ, Madejón E, Lampurlanés J, Arrúe JL, Cantero-Martínez C (2013) Soil

471 biochemical properties in a semiarid Mediterranean agroecosystem as affected by long-term tillage and

472 N fertilization. Soil Till Res 129:69-74. https://doi.org/10.1016/j.still.2013.01.005

473 Araujo R, Dunlap C, Barnett S, Franco CMM (2019) Decoding wheat endosphere-rhizosphere 
475

Asaf S, Numan M, Khan AL, Al-Harrasi A (2020) Sphingomonas: from diversity and genomics to functional role in environmental remediation and plant growth. Crit Rev Biotechnol 40:138-152. https://doi.org/10.1080/07388551.2019.1709793

Baetz U, Martinoia E (2014) Root exudates: the hidden part of plant defense. Trends Plant Sci 19:90-98. https://doi.org/10.1016/j.tplants.2013.11.006

Banerjee S, Thrall PH, Bissett A, Heijden MGA, Richardson AE (2018) Linking microbial co-occurrences to soil ecological processes across a woodland-grassland ecotone. Ecol Evol 8:8217-8230. https://doi.org/10.1002/ece3.4346

Barberán A, Bates ST, Casamayor EO, Fierer N (2012) Using network analysis to explore co-occurrence patterns in soil microbial communities. ISME J 6:343-351. https://doi.org/10.1038/ismej.2011.119 PMID:21900968

Bell E, Lamminmäki T, Alneberg J, Andersson AF, Qian C, Xiong WL, Hettich RL, Balmer L, Frutschi M, Sommer G, Bernier LR (2018) Biogeochemical cycling by a low-diversity microbial community in deep groundwater. Front Microbiol 9:1-17. https://doi.org/10.3389/fmicb.2018.02129

Bibi F, Yasir M, Song GC, Lee SY, Chung YR (2012) Diversity and characterization of endophytic bacteria associated with tidal flat plants and their antagonistic effects on Oomycetous plant pathogens.

Plant Pathol J 28:20-31. https://doi.org/10.5423/PPJ.OA.06.2011.0123

Bowles TM, Acosta-Martínez V, Calderón F, Jackson LE (2014) Soil enzyme activities, microbial 
494

495

496

497

498

499

500

501

502

503

504

505

506

507

508

509

communities, and carbon and nitrogen availability in organic agroecosystems across an intensively-managed agricultural landscape. Soil Biol Biochem 68:252-262. https://doi.org/10.1016/j.soilbio.2013.10.004

Bu RY, Ren T, Lei MJ, Liu B, Li XK, Cong RH, Zhang YY, Lu JW (2020) Tillage and straw-returning practices effect on soil dissolved organic matter, aggregate fraction and bacteria community under rice-rice-rapeseed rotation system. Agr $\quad$ Ecosyst Environ 287:1-8. https://doi.org/10.1016/j.agee.2019.106681

Cania B, Vestergaard G, Krauss M, Fliessbach A, Schloter M, Schulz S (2019) A long-term field experiment demonstrates the influence of tillage on the bacterial potential to produce soil structure-stabilizing agents such as exopolysaccharides and lipopolysaccharides. Environ Microbiome 14:1-14. https://doi.org/10.1186/s40793-019-0341-7

Chang F, Jia FA Lv R, Li Y, Wang Y, Jia QA, Zhen LS (2021) Soil bacterial communities reflect changes in soil properties during the tillage years of newly created farmland on the Loess Plateau. Appl Soil Ecol 161:1-12. https://doi.org/10.1016/j.apsoil.2020.103853

Chen YP, Wang KB, Lin YS, Shi WY, Song Y, He XH (2015) Balancing green and grain trade. Nat Geosci 8:739-741. https://doi.org/10.1038/ngeo2544

Chen YX, Wen XX, Sun YL, Zhang JL, Wu W, Liao YC (2014) Mulching practices altered soil bacterial community structure and improved orchard productivity and apple quality after five growing seasons. Sci Hortic 172:248-257. https://doi.org/10.1016/j.scienta.2014.04.010 
513 Cheng WX, Parton WJ, Gonzalez-Meler MA, Phillips R, Asao S, McNickle GG, Brzostek E, Jastrow

514 JD (2014) Synthesis and modeling perspectives of rhizosphere priming. New Phytol 201:31-44.

515 https://doi.org/10.1111/nph. 12440

516 Deng Y, Jiang YH, Yang YF, He ZL, Luo F, Zhou JZ (2012) Molecular ecological network analyses.

517 MBC Bioinformatics 13:1-20. https://doi.org/10.1186/1471-2105-13-113

518 Duran P, Jacquelinne J, Acuña-Milko A, Azcón JR, Paredes C, Rengel Z, Luz Mora M (2014)

519 Endophytic bacteria from selenium-supplemented wheat plants could be useful for plant-growth 520 promotion, biofortification and Gaeumannomyces graminis biocontrol in wheat production. Biol Fertil Soils 50:983-990. https://doi.org/10.1007/s00374-014-0920-0

Essel E, Xie JH, Deng CC, Peng ZK, Wang JB, Shen JC, Xie JH, Coulter JA, Li LL (2019) Bacterial and fungal diversity in rhizosphere and bulk soil under different long-term tillage and cereal/legume rotation. Soil Till Res 194:1-11. https://doi.org/10.1016/j.still.2019.104302

Evangelou E, Tsadilas C, Giourga C (2021) Seasonal variation of soil microbial biomass carbon and nitrogen as affected by land use in a Mediterranean agro ecosystem. Commun Soil Sci Plan 52:222-234. https://doi.org/10.1080/00103624.2020.1854298

Faust K, Raes J (2016) CoNet app: inference of biological association networks using Cytoscape.

F1000Research. 5:1-14. https://doi.org/10.12688/f1000research.9050.1

Fisher CK, Mehta P (2014) Identifying keystone species in the human gut microbiome from metagenomic timeseries using sparse linear regression. PLoS One 9:1-11. 
532

533

534

https://doi.org/10.1371/journal.pone.0102451

Gregorich EG, Wen G, Voroney RP, Kachanoski RG (1990) Calibration of a rapid direct chloroform extraction method for measuring soil microbial biomass C. Soil Biol Biochem 22:1009-1011. https://doi.org/10.1016/0038-0717(90)90148-S

Hartman K, van der Heijden MGA, Wittwer RA, Banerjee S, Walser JC, Schlaeppi K (2018) Cropping practices manipulate abundance patterns of root and soil microbiome members paving the way to smart farming. Microbiome 6:1-14. https://doi.org/10.1186/s40168-017-0389-9

Hartmann M, Niklaus PA, Zimmermann S, Schmutz S, Kremer J, Abarenkov K, Lüscher P, Widmer F, Frey B (2014) Resistance and resilience of the forest soil microbiome to logging-associated compaction. ISME J 8:226-244. https://doi.org/10.1038/ismej.2013.141

Herren CM, McMahon KD (2018) Keystone taxa predict compositional change in microbial communities. Environ Microbiol 20:2207-2217. https://doi.org/10.1111/1462-2920.14257

Hou XQ, Li R (2019) Interactive effects of autumn tillage with mulching on soil temperature, productivity and water use efficiency of rainfed potato in Loess Plateau of China. Agr Water Manage 224:1-12. https://doi.org/10.1016/j.agwat.2019.105747

Jin K, Cornelis WM, Schiettecatte W, Lu JJ, Yao YQ, Wu HJ, Gabriels D, De Neve S, Cai DX, Jin JY, Hartmann R (2007) Effects of different management practices on the soil-water balance and crop yield for improved dryland farming in the Chinese Loess Plateau. Soil Till Res 96:131-144. https://doi.org/10.1016/j.still.2007.05.002 
551

552

553

554

555

556

557

558

559

560

561

562

563

Jin K, De Neve S, Moeskops B, Lu JJ, Zhang J, Gabriels D, Cai DX, Jin JY (2008) Effects of different soil management practices on winter wheat yield and $\mathrm{N}$ losses on a dryland loess soil in China. Soil Res 46:455-463. https://doi.org/10.1071/SR07134

Jin K, Sleutel S, Buchan D, De Neve S, Cai DX, Gabriels D, Jin JY (2009) Changes of soil enzyme activities under different tillage practices in the Chinese Loess Plateau. Soil Till Res 104:115-120. https://doi.org/10.1016/j.still.2009.02.004

Jones DL, Nguyen C, Finlay RD (2009) Carbon flow in the rhizosphere: carbon trading at the soil-root interface. Plant Soil 321:5-33. https://doi.org/10.1007/s11104-009-9925-0

Kaurin A, Mihelič R, Kastelec D, Grčman H, Bru D, Philippot L, Suhadolc M (2018) Resilience of bacteria, archaea, fungi and $\mathrm{N}$-cycling microbial guilds under plough and conservation tillage, to agricultural drought. Soil Biol Biochem 120:233-245. https://doi.org/10.1016/j.soilbio.2018.02.007

Iannucci A, Canfora L, Nigro F, De Vita P, Beleggia R (2021) Relationships between root morphology, root exudate compounds and rhizosphere microbial community in durum wheat. Appl Soil Ecol 158:1-20. https://doi.org/10.1016/j.apsoil.2020.103781

López-Bellido L, Muñoz-Romero V, Fernández-García P, López-Bellido RJ (2014) Ammonium accumulation in soil: the long-term effects of tillage, rotation and $\mathrm{N}$ rate in a Mediterranean vertisol.

Soil Use Manage 30:471-479. https://doi.org/10.1111/sum.12147

Lu XL, Liao YC (2017) Effect of tillage practices on net carbon flux and economic parameters from farmland on the Loess Plateau in China. J Clean Prod 162:1617-1624. 

affected by no-tillage and conventional tillage systems in an irrigated Haploxeroll of Central Chile. Soil and water stress interact to influence arbuscular mycorrhizal fungi, rhizosphere bacteria and potential for $\mathrm{N}$ and $\mathrm{C}$ cycling in an agricultural soil. Biol Fertil Soils 55:53-66. https://doi.org/10.1007/s00374-018-1328-z https://doi.org/10.1007/s11356-014-3721-y endophytic bacteria for plant growth promoting activity in Molelwane Farm, Mafikeng, South Africa.

Naveed M, Mitter B, Yousaf S, Pastar M, Afzal M, Sessitsch A (2014) The endophyte Enterobacter sp.

FD17: a maize growth enhancer selected based on rigorous testing of plant beneficial traits and colonization characteristics. Biol Fertil Soils 50:249-262. https://doi.org/10.1007/s00374-013-0854-y 
589 (2020) Influence of plastic film mulching and planting density on yield, leaf anatomy, and root

590 characteristics of maize on the Loess Plateau. Crop J 8:548-564.

591 https://doi.org/10.1016/j.cj.2019.12.002

592 Ofek M, Hadar Y, Minz D (2012) Ecology of root colonizing Massilia (Oxalobacteraceae). PLoS One

593 7:1-12. https://doi.org/10.1371/journal.pone.0040117

594 Pareja-Sánchez E, Plaza-Bonilla D, Ramos MC, Lampurlanés J, Álvaro-Fuentes J, Cantero-Martínez C

595 (2017) Long-term no-till as a means to maintain soil surface structure in an agroecosystem transformed

596 into irrigation. Soil Till Res 174:221-230. https://doi.org/10.1016/j.still.2017.07.012

597 Qiu HS, Ge TD, Liu JY, Chen XB, Hu YJ, Wu JS, Su YR, Kuzyakov Y (2018) Effects of biotic and

598 abiotic factors on soil organic matter mineralization: Experiments and structural modeling analysis. Eur

599 J Soil Biol 84:27-34. https://doi.org/10.1016/j.ejsobi.2017.12.003

600 Rangjaroen C, Rerkasem B, Teaumroong N, Noisangiam R, Lumyong S (2015) Promoting plant

601 growth in a commercial rice cultivar by endophytic diazotrophic bacteria isolated from rice landraces.

602 Ann Microbiol 65:253-266. https://doi.org/10.1007/s13213-014-0857-4

603 Razavi BS, Blagodatskaya E, Kuzyakov Y (2016) Temperature selects for static soil enzyme systems to

604 maintain high catalytic efficiency. Soil Biol Biochem 97:15-22.

605 https://doi.org/10.1016/j.soilbio.2016.02.018

606 Schlatter DC, Paul NC, Shah DH, Schillinger WF, Bary AI, Sharratt B, Paulitz TC (2019) Biosolids

607 and tillage practices influence soil bacterial communities in dryland wheat. Microb Ecol 78:737-752. 
608

609

610

611

612

614

https://doi.org/10.1007/s00248-019-01339-1

Semenov MV, Krasnov GS, Semenov VM, van Bruggen AHC (2020) Long-term fertilization rather than plant species shapes rhizosphere and bulk soil prokaryotic communities in agroecosystems. Appl Soil Ecol 154:1-14. https://doi.org/10.1016/j.apsoil.2020.103641

Sheehy J, Regina K, Alakukku L, Six J (2015) Impact of no-till and reduced tillage on aggregation and aggregate-associated carbon in Northern European agroecosystems. Soil Till Res 150:107-113. https://doi.org/10.1016/j.still.2015.01.015

Shi YC, Lalande R, Hamel C, Ziadi N, Gagnon B, Hu ZY (2013) Seasonal variation of microbial biomass, activity, and community structure in soil under different tillage and phosphorus management practices. Biol Fertil Soils 49:803-818. https://doi.org/10.1007/s00374-013-0773-y

Singh SP, Naresh RK, Vivek, Kumar S, Kumar V, Mahajan NC, Mrunalini K, Chandra MS, Prasad KSK (2019) Conservation agriculture effects on aggregates carbon storage potential and soil microbial community dynamics in the face of climate change under semi-arid conditions: A review. J Pharmacognosy Phytochem 8:59-69

Song YN, Zhang FS, Marschner P, Fan FL, Gao HM, Bao XG, Sun JH, Li L (2007) Effect of intercropping on crop yield and chemical and microbiological properties in rhizosphere of wheat (Triticum aestivum L.), maize (Zea mays L.), and faba bean (Vicia faba L.). Biol Fertil Soils 43:565-574. https://doi.org/10.1007/s00374-006-0139-9

Spedding TA, Hamel C, Mehuys GR, Madramootoo CA (2004) Soil microbial dynamics in 
maize-growing soil under different tillage and residue management systems. Soil Biol Biochem eight years of conservation tillage on the soil physicochemical properties and bacterial communities in a rain-fed agroecosystem of the Loess Plateau, China. Land Degrad Dev 31:2475-2489. https://doi.org/10.1002/ldr.3619 agriculture based on crop rotation and tillage in the semi-arid Loess Plateau, China: effects on crop yield and soil water use. Agr Ecosyst Environ 251:67-77. https://doi.org/10.1016/j.agee.2017.09.011

Sun R, Li W, Dong W, Tian YP, Hu CS, Liu BB (2018b) Tillage changes vertical distribution of soil bacteria and fungal communities. Front Microbiol 9:699-712. https://doi.org/10.3389/fmicb.2018.00699 growth promotion and protection against diseases in associated plants. Microbial Interventions Agri Environ 263-287.

Tang LL, Zhan M, Shang CH, Yuan JY, Wan YB, Qin MG (2021) Dynamics of root exuded carbon and 643 its relationships with root traits of rapeseed and wheat. Plant Soil Environ 67:317-323. https://doi.org/10.17221/561/2020-PSE 
646

647

648

649

650

651

652

653

654

655

656

657

658

659

660

661

662 663 https://doi.org/10.1016/j.fcr.2020.107867

664 Wang Y, Li CY, Tu C, Hoyt GD, DeForest JL, Hu SJ (2017a) Long-term no-tillage and organic input

soil organic matter decomposition depend on microbial biomass-an incubation study. Soil Biol

Biochem 57:739-748. https://doi.org/10.1016/j.soilbio.2012.10.029

Thomas BW, Hunt D, Bittman S, Hannam KD, Messiga AJ, Haak D, Sharifi M, Hao XY (2019) Soil health indicators after $21 \mathrm{yr}$ of no-tillage in south coastal British Columbia. Can J Soil Sci 99:222-225. https://doi.org/10.1139/cjss-2018-0146

Toju H, Peay KG, Yamamichi M, Narisawa K, Hiruma K, Naito K, Fukuda S, Ushio M, Nakaoka S, Onoda Y, Yoshida K, Schlaeppi K, Bai Y, Sugiura R, Ichihashi Y, Minamisawa K, Kiers ET (2018) Core microbiomes for sustainable agroecosystems. Nat Plants 4:247-257. https://doi.org/10.1038/s41477-018-0139-4

Tyler HL (2019) Bacterial community composition under long-term reduced tillage and no till management. J Appl Microbiol 126:1797-1807. https://doi.org/10.1111/jam.14267

Wang JY, Zou JW (2020a) No-till increases soil denitrification via its positive effects on the activity and abundance of the denitrifying community. Soil Biol Biochem 142:1-8. https://doi.org/10.1016/j.soilbio.2020.107706

Wang SL, Wang H, Muhammad BH, Zhang Q, Yu Q, Wang R, Wang XL, Li J (2020b) No-tillage and subsoiling increased maize yields and soil water storage under varied rainfall distribution: A 9-year 662 site-specific study in a semi-arid environment. Field Crop Res 255:1-9. 
665 management enhanced the diversity and stability of soil microbial community. Sci Total Environ

671 the rhizosphere bacterial community throughout crop growth. Soil Till Res 197:1-10.

672 https://doi.org/10.1016/j.still.2019.104501

673 Wang ZT, Liu L, Chen Q, Wen XX, Liao YC (2016) Conservation tillage increases soil bacterial 674 diversity in the dryland of northern China. Agro Sustain Dev 36:1-9. 675 https://doi.org/10.1007/s13593-016-0366-x

676 Wang ZT, Li T, Wen XX, Liu Y, Han J, Liao YC, DeBruyn J.M (2017b) Fungal communities in 677 rhizosphere soil under conservation tillage shift in response to plant growth. Front Microbiol 8:1-11. 678 https://doi.org/10.3389/fmicb.2017.01301

679 Wang ZT, Liu L, Chen Q, Wen XX, Liu YC, Han J, Liao YC (2017c) Conservation tillage enhances the 680 stability of the rhizosphere bacterial community responding to plant growth. Agro Sustain Dev 37:1-11. 681 https://doi.org/10.1007/s13593-017-0454-6 Xia Q, Liu XL, Gao ZQ, Wang JM, Yang ZP (2020) Responses of rhizosphere soil bacteria to 2-year 683 tillage rotation treatments during fallow period in semiarid southeastern Loess Plateau. Peer J 
684

685

686

687

688

689

690

691

692

693

694

695

696

697

698

699

8:8853-8877. https://doi.org/10.7717/peerj.8853

Yan SS, Song JM, Fan JS, Yan C, Dong SK, Ma CM, Gong ZP (2020) Changes in soil organic carbon fractions and microbial community under rice straw return in Northeast China. Glob Ecol Conserv 22:1-12. https://doi.org/10.1016/j.gecco.2020.e00962

Yang YH, Ding JL, Zhang YH, Wu JC, Zhang JM, Pan XY, Gao CM, Wang Y, He F (2018) Effects of tillage and mulching measures on soil moisture and temperature, photosynthetic characteristics and yield of winter wheat. Agr Water Manage 201:299-308. https://doi.org/10.1016/j.agwat.2017.11.003

Zhang HH, Zhang YQ, Yan CG, Liu EK, Chen BQ (2016) Soil nitrogen and its fractions between long-term conventional and no-tillage systems with straw retention in dryland farming in northern China. Geoderma 269:138-144. https://doi.org/10.1016/j.geoderma.2016.02.001

Zhang JY, Zhang N, Liu YX, Zhang XN, Hu B, Qin Y, Xu HR, Wang W, Guo XX, Qian JM, Wang W, Zhang PF, Jin T, Chu CC, Bai Y (2018) Root microbiota shift in rice correlates with resident time in the field and developmental stage. Sci China Life Sci 61:613-621. https://doi.org/10.1007/s11427-018-9284-4

Zhao ML, Zhao J, Yuan J, Hale L, Wen T, Huang QW, Vivanco JM, Zhou JZ, Kowalchuk GA, Shen QR (2020) Root exudates drive soil-microbe-nutrient feedbacks in response to plant growth. Plant Cell Environ 44:613-628. https://doi.org/10.1111/PCE.13928

Zhou H, Gao Y, Jia XH, Wang MM, Ding JJ, Cheng L, Bao F, Wu B (2020) Network analysis reveals the strengthening of microbial interaction in biological soil crust development in the Mu Us sandy land, 
704 Zuber SM, Villamil MB (2016) Meta-analysis approach to assess effect of tillage on microbial biomass

705 and enzyme activities. Soil Biol Biochem 97:176-187. https://doi.org/10.1016/j.soilbio.2016.03.011 
707 Fig. 1 Non-metric multidimensional scaling analysis of the rhizo-bacterial community structure under tillage 708 treatments across crop growth. CT, conventional tillage; NT, no tillage with mulch; RT, reduced tillage; SS, 709 subsoiling with mulch; e, elongation stage; g, grain filling stage

Fig. 2 The relative abundance of phyla (a) and genera (b) under different tillage practices at the elongation and grain filling stages. CT, conventional tillage; RT, reduced tillage; NT, no tillage with mulch; SS, subsoiling with mulch

Fig. 3 Effect of long-term tillage practices (a: conventional tillage; b: reduced tillage; c: no tillage with mulch; d: subsoiling with mulch) on the keystone genera at the elongation and grain filling stages. The nodes with color represent keystone genera. The triangles represent keystone OTUs in keystone genera. The color outside nodes represents corresponding phylum. Red lines represent copresence, blue lines represent mutual exclusion

Fig. 4 Correlations between edaphic characteristics and keystone genera under different tillage regimes at the elongation stage (a) and grain filling stage (b). CT, conventional tillage; RT, reduced tillage; NT, no tillage with biomass nitrogen 
Figures

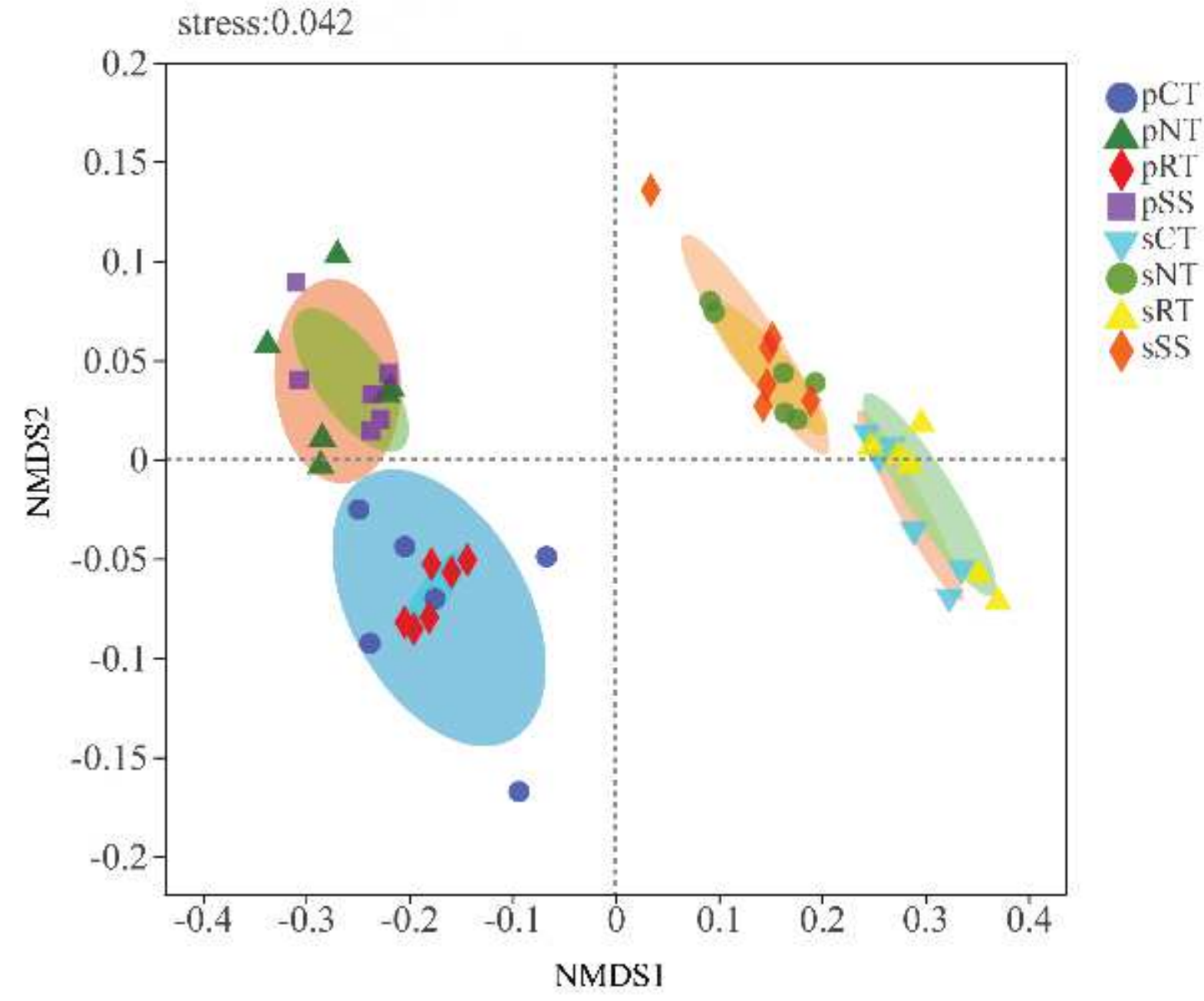

Figure 1

Non-metric multidimensional scaling analysis of the rhizo-bacterial community structure under tillage treatments across crop growth. CT, conventional tillage; NT, no tillage with mulch; RT, reduced tillage; SS, subsoiling with mulch; e, elongation stage; g, grain filling 

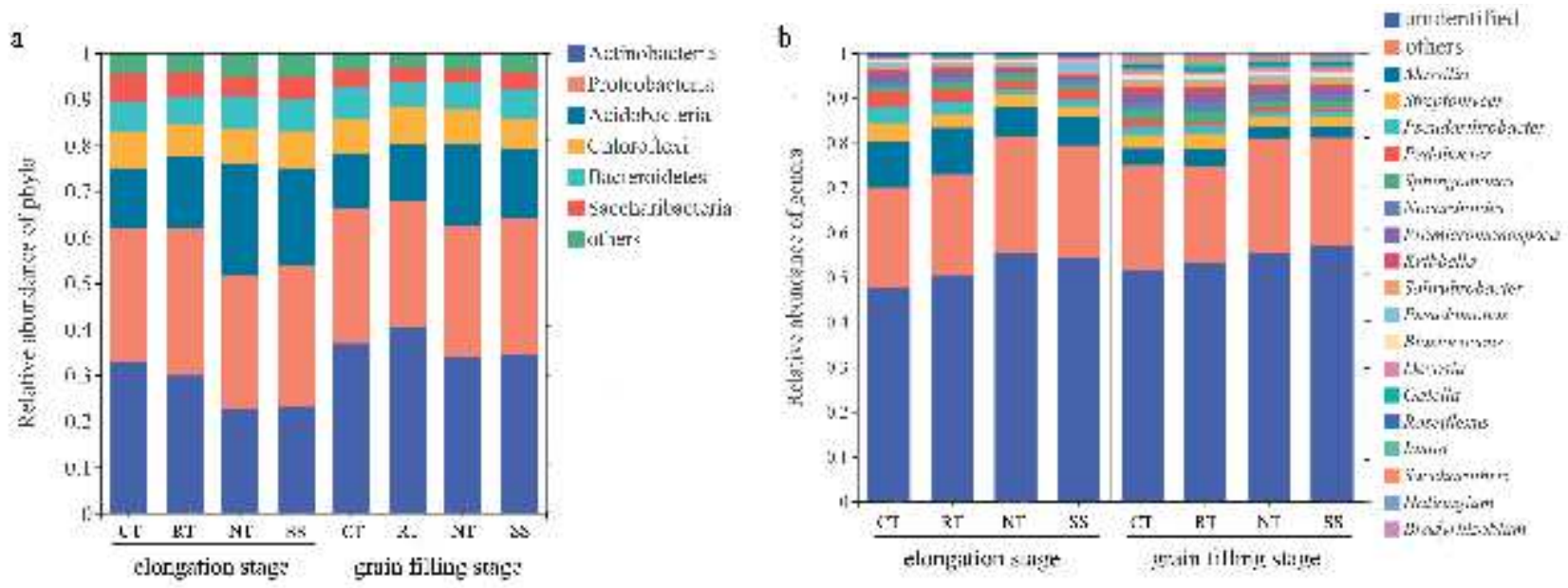

Figure 2

The relative abundance of phyla (a) and genera (b) under different tillage practices at the elongation and grain filling stages. CT, conventional tillage; RT, reduced tillage; NT, no tillage with mulch; SS, subsoiling with mulch 


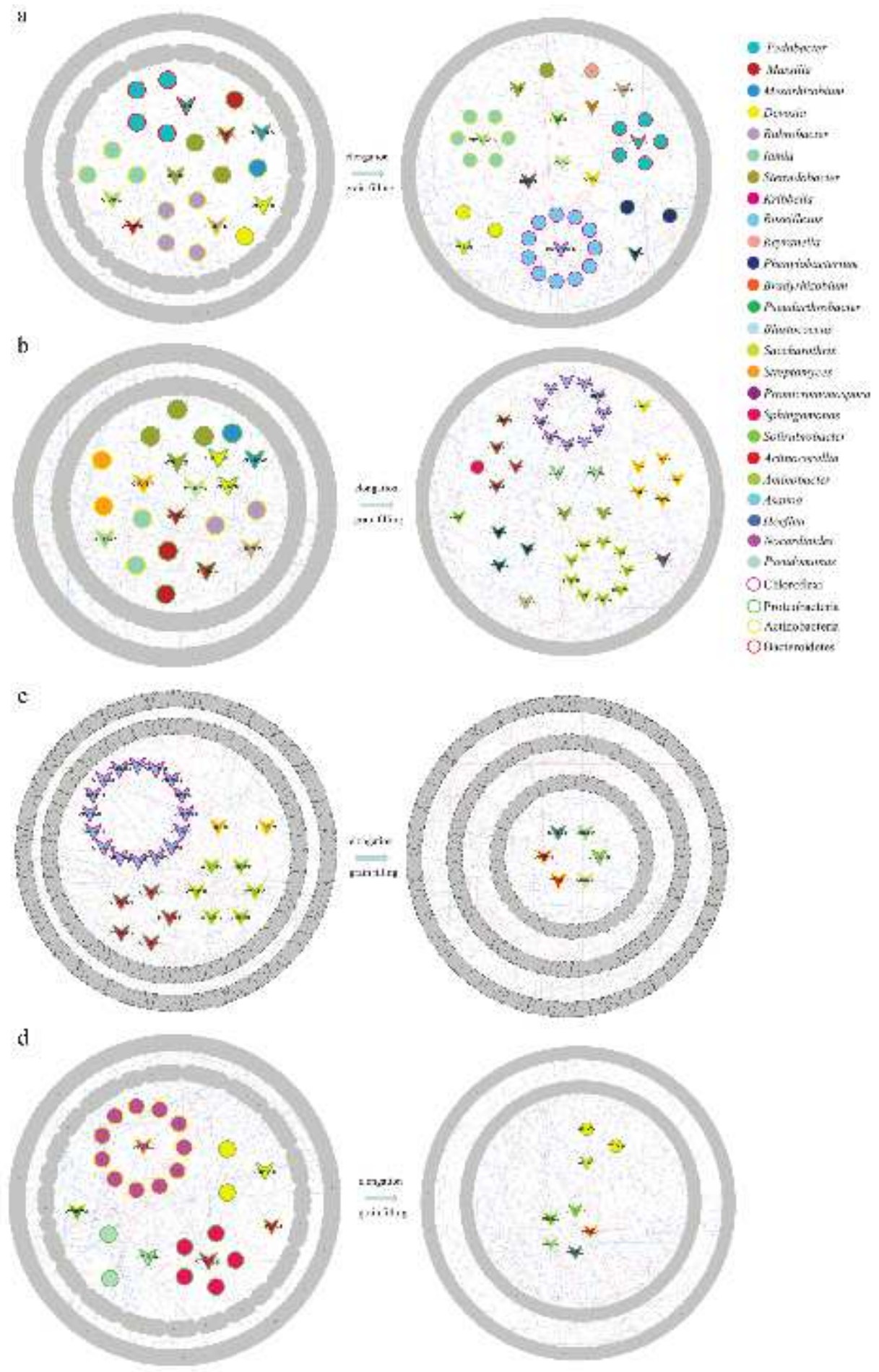

\section{Figure 3}

Effect of long-term tillage practices (a: conventional tillage; b: reduced tillage; c: no tillage with mulch; d: subsoiling with mulch) on the keystone genera at the elongation and grain filling stages. The nodes with color represent keystone genera. The triangles represent keystone OTUs in keystone genera. The color outside nodes represents corresponding phylum. Red lines represent copresence, blue lines represent mutual exclusion 
a

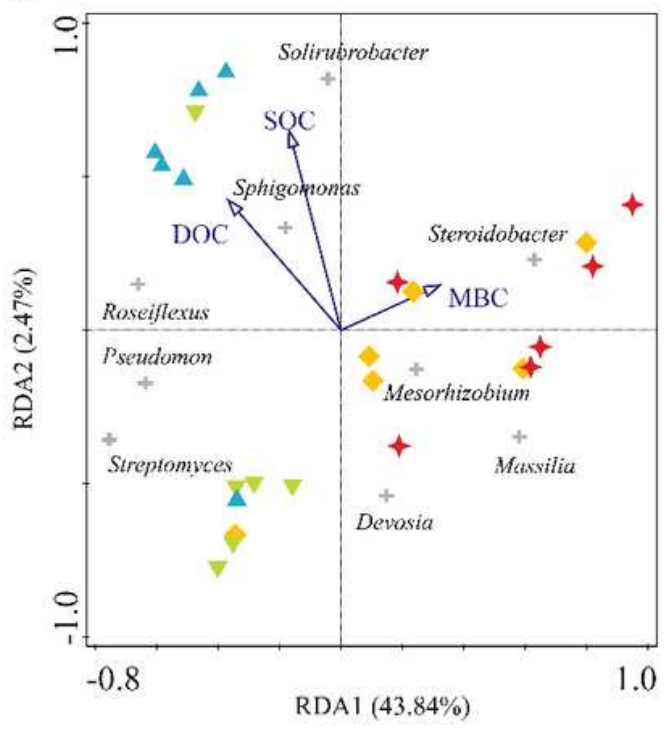

b

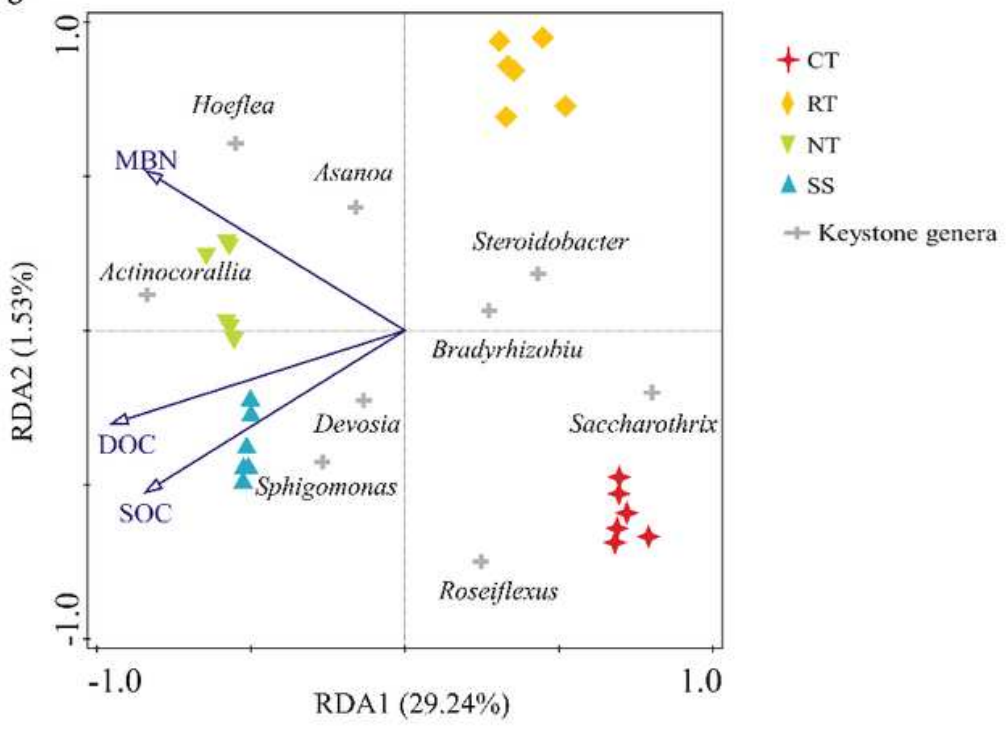

\section{Figure 4}

Correlations between edaphic characteristics and keystone genera under different tillage regimes at the elongation stage (a) and grain filling stage (b). CT, conventional tillage; RT, reduced tillage; NT, no tillage with mulch; SS, subsoiling with mulch; SOC, soil organic carbon; DOC, dissolved organic carbon; MBN, microbial biomass

\section{Supplementary Files}

This is a list of supplementary files associated with this preprint. Click to download.

- Table.pdf

- Supplementarymaterials.pdf 